\title{
Calculation of Fermentation Parameters from the Results of a Fed-Batch Test Taking Account of the Volume of Biomass in the Fermenting Medium
}

\author{
Walter Borzani* "in memoriam" \\ Instituto Mauá de Tecnologia; Escola de Engenharia Mauá; Praça Mauá 1; borzani@maua.br; 09580-900; São \\ Caetano do Sul - SP - Brazil
}

\begin{abstract}
The volume of biomass in the fermenting medium may significantly affect the values of fermentation parameters calculated from the measured concentrations of the substrates and/or products. The corrections proposed in this paper should be evaluated and, depending on their magnitude, considered in order to obtain more representative results. A numerical example is presented.
\end{abstract}

Key words: Biomass volume, corrections calculation, fed-batch fermentation, fermentation parameters, medium aqueous phase volume

\section{INTRODUCTION}

The values of the fermentation parameters (yield factors; efficiencies; productivities; production and consumption rates), usually calculated from the measured concentrations of the biomass, substrates and products, may be significantly influenced by several factors (e.g. evaporation and stripping losses, addition of the acid or base solutions to control the medium $\mathrm{pH}$, addition of antifoam, production of substances that change the aqueous phase volume, biomass volume, samples withdrawal). Some aspects of the above topics have been discussed elsewhere (Borzani and Perego, 1976; Concone et al., 1978; Wang, 1979; Borzani and Baralle, 1983; Borzani, 1995; Borzani and Jurkiewicz, 1998; Borzani, 2003). The main purpose of this paper was to show to what extent the biomass volume in the fermenting medium could affect the values of the fermentation parameters calculated from results of a fed-batch experiment.

\section{Aqueous Phase Volume}

Considering that the biomass concentrations are measured in the whole medium, and that the substrate and product concentrations are measured in the medium aqueous phase, that is, in the filtered (or centrifuged) medium, it is necessary to evaluate the aqueous phase volume in order to calculate the actual masses of the substrate and product in the fermenting medium. Equation (1), where $V_{a}$ is the volume of the aqueous phase, $V$ is the volume of the fermenting medium, $X$ is the biomass concentration (dry matter), $\sigma$ is the fraction of dry matter in the biomass, and $\rho$ is the density of the microorganism, permits to calculate the above volume.

$$
V_{a}=V \cdot\left(1-\frac{X}{\sigma \cdot \rho}\right)
$$

*Author for correspondence 
Otherwise, the volume of the fermenting medium in the reactor at time $\mathrm{t}(t \leq \theta$, where $\theta$ is the duration of the reactor feeding phase) is calculated by Equation (2), where $V_{i}$ is the volume of the inoculum, and $F$ is the reactor feeding rate.

$$
V=V_{i}+\int_{o}^{t} F \cdot d t
$$

Here it was assumed that $F$ was constant and that $V$ was not affected by the other operational conditions.

The actual masses of the biomass $\left(M_{X}\right)$, substrate $\left(M_{S}\right)$ and product $\left(M_{P}\right)$ in the reactor were then calculated by Equations (3), (4) and (5), respectively, where $S$ and $P$ were, the concentrations of substrate and product respectively, measured in the aqueous phase of the fermenting medium.

$$
\begin{aligned}
& M_{X}=X \cdot V \\
& M_{S}=S \cdot V \cdot\left(1-\frac{X}{\sigma \cdot \rho}\right) \\
& M_{P}=P \cdot V \cdot\left(1-\frac{X}{\sigma \cdot \rho}\right)
\end{aligned}
$$

It was proposed (Borzani, 2003) to replace $S$ and $P$ (measured in $\mathrm{g} / \mathrm{L}$ aqueous phase), respectively, by $S^{\prime}$ and $P^{\prime}$ (measured in $\mathrm{g} / \mathrm{L}$ whole medium) calculated by Equations (6) and (7).

$$
\begin{aligned}
& S^{\prime}=S \cdot\left(1-\frac{X}{\sigma \cdot \rho}\right) \\
& P^{\prime}=P \cdot\left(1-\frac{X}{\sigma \cdot \rho}\right)
\end{aligned}
$$

Obviously, depending on both the value of $X / \sigma \cdot \rho$ and the uncertainty associated with the measured concentration, the difference between the measured and the corresponding calculated concentration could be insignificant (Borzani, 2003).

\section{General Equations}

The purpose of this section was to compare the values of a fermentation parameter calculated from the measured concentrations disregarding the biomass volume obtained taking account of the above volume. In the equations presented in this section, $S_{0}$ was the substrate concentration of the feeding mash, and the subscript $i$ and $f$ indicate, respectively, the variable values at time $t=0$ and $t$ $=\theta$. If the value of a given parameter calculated disregarding the biomass volume was represented by $Z$, the value calculated taking account of the biomass volume would be represented by $Z$ '.

Biomass yield factors $\left(Y_{X}\right.$ and $\left.Y_{X}^{\prime}\right)$

$$
\begin{aligned}
& Y_{X}=\frac{V_{f} \cdot X_{f}-V_{i} \cdot X_{i}}{F \cdot \theta \cdot S_{0}+V_{i} \cdot S_{i}-V_{f} \cdot S_{f}} \\
& Y_{X}^{\prime}=\frac{V_{f} \cdot X_{f}-V_{i} \cdot X_{i}}{F \cdot \theta \cdot S_{0}+V_{i} \cdot S_{i}^{\prime}-V_{f} \cdot S_{f}^{\prime}}
\end{aligned}
$$

Equations (6), (8) and (9) show that: a) $Y_{X}>Y_{X}^{\prime}$ when $S_{i}=0$; b) $Y_{X}<Y_{X}^{\prime}$ when $S_{f}=0$; c) $Y_{X}=Y_{X}^{\prime}$ when $S_{i}=S_{f}=0$. Considering that $S_{i}$ and $S_{f}$ were usually relatively small, the difference between $Y_{X}$ and $Y_{X}^{\prime}$ would be frequently insignificant.

Product yield factors $\left(Y_{P}\right.$ and $\left.Y_{P}^{\prime}\right)$

$$
\begin{aligned}
& Y_{P}=\frac{V_{f} \cdot P_{f}-V_{i} \cdot P_{i}}{F \cdot \theta \cdot S_{0}+V_{i} \cdot S_{i}-V_{f} \cdot S_{f}} \\
& Y_{P}^{\prime}=\frac{V_{f} \cdot P_{f}^{\prime}-V_{i} \cdot P_{i}^{\prime}}{F \cdot \theta \cdot S_{0}+V_{i} \cdot S_{i}^{\prime}-V_{f} \cdot S_{f}^{\prime}}
\end{aligned}
$$

If $S_{i}=S_{f}=P_{i}=0$, Equations (6), (7), (10) and (11) lead to Equation (12).

$$
\frac{Y_{P}^{\prime}}{Y_{P}}=1-\frac{X_{f}}{\sigma \cdot \rho}
$$

\section{Process productivities ( $Q$ and $Q^{\prime}$ )}

$$
\begin{aligned}
& Q=\frac{V_{f} \cdot P_{f}-V_{i} \cdot P_{i}}{V_{f} \cdot t_{f}} \\
& Q^{\prime}=\frac{V_{f} \cdot P_{f}^{\prime}-V_{i} \cdot P_{i}^{\prime}}{V_{f} \cdot t_{f}}
\end{aligned}
$$


If $P_{i}=0$, Equations (7), (13) and (14) give:

$$
\frac{Q^{\prime}}{Q}=1-\frac{X_{f}}{\sigma \cdot \rho}
$$

Rates during the reactor filling phase

The rates of biomass growth $\left(R_{X}\right)$, product formation $\left(R_{P}\right.$ and $\left.R_{P}^{\prime}\right)$ and substrate consumption $\left(R_{S}\right.$ and $\left.R_{S}^{\prime}\right)$ during the reactor filling phase may be calculated by equations (16) to $(20)$.

$$
\begin{aligned}
& R_{X}=D \cdot X+\frac{d X}{d t} \\
& R_{P}=D \cdot P+\frac{d P}{d t} \\
& R_{P}^{\prime}=D \cdot P^{\prime}+\frac{d P^{\prime}}{d t} \\
& R_{S}=D \cdot\left(S_{0}-S\right)-\frac{d S}{d t}
\end{aligned}
$$

$$
R_{S}^{\prime}=D \cdot\left(S_{0}-S^{\prime}\right)-\frac{d S^{\prime}}{d t}
$$

Equations (7), (17) and (18) give:

$$
R_{P}^{\prime}=\left(1-\frac{X}{\sigma \cdot \rho}\right) \cdot R_{P}-\frac{P}{\sigma \cdot \rho} \cdot \frac{d X}{d t}
$$

Otherwise, Equations (6), (16), (19) and (20) lead to Equation (22).

$$
R_{S}^{\prime}=R_{S}+\frac{S}{\sigma \cdot \rho} \cdot R_{X}+\frac{X}{\sigma \cdot \rho} \cdot \frac{d S}{d t}
$$

\section{Numerical Example}

Table 1 shows the results obtained during the reactor filling phase of a fed-batch ethanol fermentation of sugar-cane molasses medium carried out under the following experimental conditions (Koshimizu, 1984; Koshimizu et al., 1984): $V_{i}=4.00 \mathrm{~L}, S_{i}=P_{i}=0, S_{0}=247 \mathrm{~g} / \mathrm{L}, F=$ $1.17 \mathrm{~L} / \mathrm{h}$ and $\theta=5 \mathrm{~h}$.

Table 1 - Biomass $(X)$, substrate $(S)$ and ethanol $(P)$ concentrations during the reactor filling phase.

\begin{tabular}{cccc}
\hline $\boldsymbol{t}(\boldsymbol{h})$ & $\boldsymbol{X}(\boldsymbol{g} / \boldsymbol{L})$ & $\boldsymbol{S}(\boldsymbol{g} / \mathbf{L})$ & $\boldsymbol{P}(\boldsymbol{g} / \mathbf{L})$ \\
\hline 0 & 33.1 & 0 & 0 \\
1 & 28.5 & 18.3 & 15.7 \\
2 & 24.5 & 28.2 & 26.2 \\
3 & 22.8 & 31.1 & 34.8 \\
4 & 22.2 & 29.7 & 43.8 \\
5 & 21.9 & 26.2 & 51.3 \\
\hline
\end{tabular}

In the case of ethanol fermentation, the concentration of intracellular ethanol would be equal to the concentration of ethanol in the medium aqueous phase (Pamment and Dasari, 1988). Hence, if the purpose of the test is to study the process performance taking account of both the intracellular and the extracellular ethanol, the values of $P, P_{f}$ and $P_{i}$ could be used in Equations (11), (14) and (18) instead of $P^{\prime}, P_{f}^{\prime}$ and $P_{i}^{\prime}$, respectively. If, however, the purpose would be to study the process performance taking account of only the extracellular ethanol, since only the medium aqueous phase is distilled, Equations (11), (14) and (18) must be used. Calling $Y_{P}^{\prime \prime}, Q^{\prime \prime}$ and $R_{P}^{\prime \prime}$ the ethanol yield factor, the process productivity and the ethanol production rate, respectively, calculated taking account of both the extracellular and the intracellular ethanol, Equation (23) to (25) must be used.

$$
\begin{aligned}
& Y_{P}^{\prime \prime}=\frac{V_{f} \cdot P_{f}-V_{i} \cdot P_{i}}{F \cdot \theta \cdot S_{0}+V_{0} \cdot S_{i}^{\prime}-V_{f}} \\
& Q^{\prime \prime}=\frac{V_{f} \cdot P_{f}-V_{i} \cdot P_{i}}{V_{f} \cdot t_{f}}=Q \\
& R_{P}^{\prime \prime}=D \cdot P+\frac{d P}{d t}=R_{P}
\end{aligned}
$$

Table 2 shows the calculated values of $V, D, S^{\prime}$ and $P^{\prime}$ during the reactor feeding phase. The 
values of $\sigma$ and $\rho$ were 0.300 and $1.10 \cdot 10^{3} \mathrm{~g} / \mathrm{L}$, respectively.

The values of Tables 1 and 2 permit to calculate the biomass yield factors $\left(Y_{X}=0.182 \mathrm{~g} / \mathrm{g}\right.$; $\left.Y_{X}^{\prime}=0.179 \mathrm{~g} / \mathrm{g}\right)$, the ethanol yield factors $\left(Y_{P}=\right.$ $\left.0.426 \mathrm{~g} / \mathrm{g} ; Y_{P}^{\prime}=0.392 \mathrm{~g} / \mathrm{g} ; Y_{P}^{\prime \prime}=0.420 \mathrm{~g} / \mathrm{g}\right)$ and the process productivities $\left(Q=Q^{\prime \prime}=10.3 \mathrm{~g} / \mathrm{L} . \mathrm{h}\right.$; $\left.Q^{\prime}=9.6 \mathrm{~g} / \mathrm{L} . \mathrm{h}\right)$.

The above values showed that $Y_{X}$ was $1.7 \%$ higher than $Y_{X}^{\prime}, Y_{P}$ was $1.4 \%$ higher than $Y_{P}^{\prime \prime}$ and $8.7 \%$ higher than $Y_{P}^{\prime}$, and $Q=Q^{\prime \prime}$ was $7.3 \%$ higher than $Q^{\prime}$. It was then possible to conclude that, in this example, the volume of the biomass in the fermenting medium: a) did not affect the calculated value of the biomass yield factor; $b$ ) did not affect the calculated values of the ethanol yield factor and process productivity when the intracellular ethanol was also considered; c) affected the values of the ethanol yield factor and process productivity when only the extracellular ethanol was considered.

From the curves representing the variation of $S, P$, $S^{\prime}$ and $P^{\prime}$ during the filling phase, the values of $R_{S}, R_{P}, R_{S}^{\prime}$ and $R_{P}^{\prime}$ were calculated (see Table 3 ). The numerical differentiation method (Sinclair and Cantero, 1990) was used to calculate the $d S / d t$, $d P / d t, d S^{\prime} / d t$ and $d P^{\prime} / d t$.

Assuming that the difference $R_{S}-R_{S}^{\prime}$ (or $\left.R_{P}-R_{P}^{\prime}\right)$ could be considered as negligible if $R_{S} / R_{S}^{\prime}$ (or $R_{P} / R_{P}^{\prime}$ ) belonged to the interval 0.980 to 1.020 , Table 3 showed that the volume of the biomass in the fermenting medium affected the value of the ethanol production rate. The above volume, however, did not affect the value of the substrate consumption rate when $t \geq 1.75 \mathrm{~h}$.

Table 2 - Calculated values of the fermenting medium volume $(V)$, dilution rate $(D)$ and concentrations of substrate $\left[S^{\prime}\right.$, Equation (6)] and ethanol $\left[P^{\prime}\right.$, Equation (7)] during the reactor filling phase.

\begin{tabular}{ccccc}
\hline $\boldsymbol{t}(\boldsymbol{h})$ & $\boldsymbol{V}(\boldsymbol{L})$ & $\boldsymbol{D}\left(\boldsymbol{h}^{-\boldsymbol{1}}\right)$ & $\boldsymbol{S}^{\prime}(\boldsymbol{g} / \boldsymbol{L})$ & $\boldsymbol{P} \boldsymbol{\prime}^{\prime}(\boldsymbol{g} / \mathbf{L})$ \\
\hline 0 & 4.00 & 0.292 & 0 & 0 \\
1 & 5.17 & 0.226 & 16.7 & 14.3 \\
2 & 6.34 & 0.184 & 24.1 & 24.2 \\
3 & 7.51 & 0.156 & 28.9 & 32.4 \\
4 & 8.68 & 0.135 & 27.7 & 40.8 \\
5 & 9.85 & 0.119 & 24.5 & 47.9 \\
\hline
\end{tabular}

Table 3 - Substrate consumption rates $\left(R_{S}\right.$ and $\left.R_{S}^{\prime}\right)$ and ethanol production rates $\left(R_{P}\right.$ and $\left.R_{P}^{\prime}\right)$ during the reactor filling phase

\begin{tabular}{ccccccc}
$\begin{array}{c}\boldsymbol{t} \\
\text { (h) }\end{array}$ & $\begin{array}{c}\boldsymbol{R}_{S} \\
\mathbf{( * )}^{*}\end{array}$ & $\begin{array}{c}R_{S}^{\prime} \\
(*)\end{array}$ & $\begin{array}{c}R_{S} \\
R_{S}^{\prime}\end{array}$ & $\begin{array}{c}\boldsymbol{R}_{\boldsymbol{P}} \\
(*)\end{array}$ & $\begin{array}{c}R_{P}^{\prime} \\
(*)\end{array}$ & $\begin{array}{c}R_{P} \\
R_{P}^{\prime}\end{array}$ \\
\hline 0.25 & 45.6 & 47.8 & 0.954 & 19.9 & 17.7 & 1.124 \\
0.75 & 39.7 & 41.2 & 0.964 & 15.8 & 14.7 & 1.075 \\
1.25 & 36.3 & 37.5 & 0.968 & 14.9 & 13.8 & 1.080 \\
1.75 & 34.8 & 35.4 & 0.983 & 15.2 & 13.8 & 1.101 \\
2.25 & 34.3 & 34.9 & 0.982 & 13.4 & 12.6 & 1.063 \\
2.75 & 33.2 & 33.6 & 0.988 & 13.7 & 12.9 & 1.062 \\
3.25 & 33.4 & 32.9 & 1.015 & 14.0 & 13.1 & 1.069 \\
3.75 & 31.9 & 32.5 & 0.981 & 14.1 & 13.3 & 1.060 \\
4.25 & 31.8 & 31.4 & 1.013 & 14.3 & 13.4 & 1.067 \\
4.75 & 30.4 & 30.6 & 0.993 & 14.5 & 13.6 & 1.066 \\
\hline
\end{tabular}




\section{NOMENCLATURE}

$D \quad$ dilution rate $\left(\mathrm{h}^{-1}\right)$

$F \quad$ reactor feeding rate $(\mathrm{L} / \mathrm{h})$

$M_{P} \quad$ mass of product in the fermenting medium (g)

$M_{S} \quad$ mass of substrate in the fermenting medium $(\mathrm{g})$

$M_{X}$ mass of biomass in the fermenting medium $(\mathrm{g})$

$P$ product concentration measured in the aqueous phase $(\mathrm{g} / \mathrm{L})$

$P^{\prime} \quad$ product concentration calculated by Equation $(7)(\mathrm{g} / \mathrm{L})$

$Q \quad$ process productivity $(*)(\mathrm{g} / \mathrm{L} . \mathrm{h})$

$Q^{\prime} \quad$ process productivity $(* *)(\mathrm{g} / \mathrm{L} . \mathrm{h})$

$R_{P} \quad$ product production rate $(*)(\mathrm{g} / \mathrm{L} . \mathrm{h})$

$R_{P}^{\prime} \quad$ product production rate $(* *)(\mathrm{g} / \mathrm{L} . \mathrm{h})$

$R_{S} \quad$ substrate consumption rate $(*)(\mathrm{g} / \mathrm{L} . \mathrm{h})$

$R_{S}^{\prime} \quad$ substrate consumption rate $(* *)(\mathrm{g} / \mathrm{L} . \mathrm{h})$

$R_{X} \quad$ biomass growth rate (g/L.h)

$S$ substrate concentration measured in the aqueous phase $(\mathrm{g} / \mathrm{L})$

$S^{\prime} \quad$ substrate concentration calculated by Equation $(6)(\mathrm{g} / \mathrm{L})$

$S_{0} \quad$ substrate concentration of the feeding $\operatorname{mash}(\mathrm{g} / \mathrm{L})$

t time (h)

$\mathrm{V} \quad$ volume of the fermenting medium (L)

$V_{a} \quad$ volume of the aqueous phase (L)

$V_{i} \quad$ volume of the inoculum (L)

$X \quad$ biomass concentration (dry matter) $(\mathrm{g} / \mathrm{L})$

$Y_{P} \quad$ product yield factor $(*)(\mathrm{g} / \mathrm{g})$

$Y_{P}^{\prime} \quad$ product yield factor $(* *)(\mathrm{g} / \mathrm{g})$

$Y_{X} \quad$ biomass yield factor $(*)(\mathrm{g} / \mathrm{g})$

$Y_{X}^{\prime} \quad$ biomass yield factor $(* *)(\mathrm{g} / \mathrm{g})$

$\theta \quad$ duration of the reactor feeding phase (h)

$\rho \quad$ density of the microorganism $(\mathrm{g} / \mathrm{L})$

$\sigma \quad$ fraction of dry matter in the biomass (-)

$i \quad$ subscript indicating the value at $\mathrm{t}=0$

$f \quad$ subscript indicating the value at $\mathrm{t}=\theta$

(*) calculated disregarding the biomass volume

(**) calculated taking account of the biomass volume

\section{RESUMO}

O volume da biomassa no meio em fermentação pode afetar significativamente os parâmetros do processo calculados a partir das medidas das concentrações de substratos e/ou produtos. Correções propostas neste trabalho deveriam ser avaliadas e, dependendo de seus valores, consideradas a fim de obter resultados mais representativos. Apresenta-se um exemplo numérico.

\section{REFERENCES}

Borzani, W. (1995), Product inhibition during the feeding phase in fed-batch ethanol fermentation of sugar-cane blasckstrap molasses. Biotechnol. Lett., 17, 1295-1298.

Borzani, W. (2003), Calculation of fermentation parameters from the results of a batch test taking account of the volume of biomass in the fermenting medium. Biotechnol. Lett. 25, 1953-1956. See Erratum: Biotechnol. Lett, 26, 357-362.

Borzani, W. and Baralle, S.B. (1983), Correction of results obtained in laboratory-scale studies of batch fermentation kinetics. Biotechnol. Bioeng., 25, 32013206.

Borzani, W. and Jurkiewicz, C.H. (1998), Variation of the ethanol yield during very rapid batch fermentation of sugar-cane blasckstrap molasses. Brazil. J. Chem. Eng., 15, 225-233.

Borzani, W. and Perego Jr., L. (1976), The mash volume decrease during the ethanol fermentation of blackstrap molasses. J. Ferment. Technol., 54, 902906.

Concone, B.R.V.; Doin, P.A. and Pinto, A.G. (1978), Some major deviations for biomass determination by indirect method and estimation based on alkali consumption. J. Ferment. Technol., 56, 59-63.

Koshimizu, L.H. (1984), Influência da concentração inicial de levedura e do tempo de alimentação da dorna no processo descontínuo alimentado de fermentação alcoólica de mosto de melaço de canade-açúcar. MSc Thesis, University of São Paulo, São Paulo, Brazil.

Koshimizu, L.H., Gómez, E.I.V., Bueno Netto, C.L. Cruz, M.R.M., Vairo, M.L.R. and Borzani, W. (1984), Constant fed-batch ethanol fermentation of molasses. J. Ferment. Technol., 62, 205-210.

Pamment, N.B. and Dasari, G. (1988), Intracellular ethanol concentration and its estimation. In: van Udden, N.F. (Ed.). Ethanol Inhibition in Yeasts and Bacteria. CRC Press, Boca Raton, Florida. 
Sinclair, C.G. and Cantero, D. (1990), Fermentation modeling. In: Mc Neil, B. and Harvey, L.M. (Eds.). Fermentation: a practical approach. IRL Press, Oxford.

Wang, H.I. (1979), Volume changes during aerobic fermentations. Biotechnol. Bioeng., 21, 525-532.

Received: June 01, 2007;

Revised: November 19, 2007;

Accepted: April 03, 2008. 